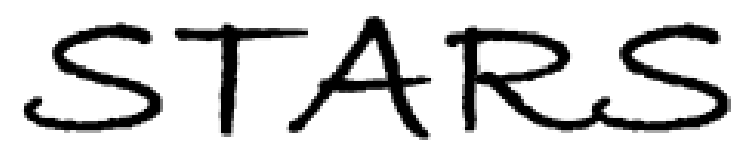

University of Central Florida

STARS

$1-1-1997$

\title{
Mathematical modeling of melting during laser materials processing
}

J. Xie

University of Central Florida

A. Kar

University of Central Florida

Find similar works at: https://stars.library.ucf.edu/facultybib1990

University of Central Florida Libraries http://library.ucf.edu

This Article is brought to you for free and open access by the Faculty Bibliography at STARS. It has been accepted for inclusion in Faculty Bibliography 1990s by an authorized administrator of STARS. For more information, please contact STARS@ucf.edu.

\section{Recommended Citation}

Xie, J. and Kar, A., "Mathematical modeling of melting during laser materials processing" (1997). Faculty Bibliography 1990s. 2139.

https://stars.library.ucf.edu/facultybib1990/2139

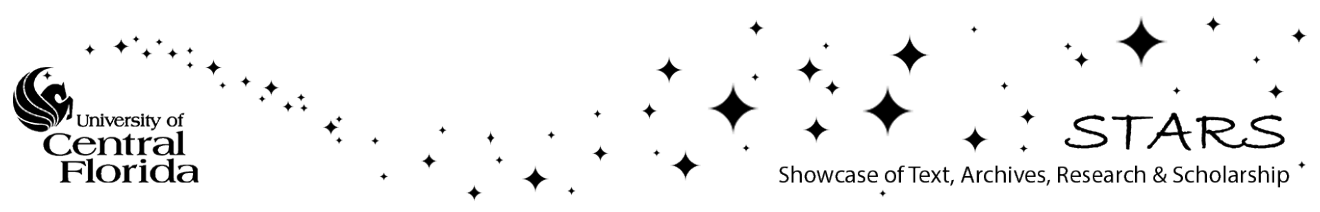




\section{Mathematical modeling of melting during laser materials processing}

Cite as: Journal of Applied Physics 81, 3015 (1997); https://doi.org/10.1063/1.364336

Submitted: 24 April 1996 . Accepted: 27 December 1996 . Published Online: 04 June 1998

J. Xie, and A. Kar

\section{ARTICLES YOU MAY BE INTERESTED IN}

Heat transfer model for cw laser material processing

Journal of Applied Physics 51, 941 (1980); https://doi.org/10.1063/1.327672

Heat treating and melting material with a scanning laser or electron beam

Journal of Applied Physics 48, 3895 (1977); https://doi.org/10.1063/1.324261

Dynamics of keyhole and molten pool in laser welding

Journal of Laser Applications 10, 247 (1998); https://doi.org/10.2351/1.521858

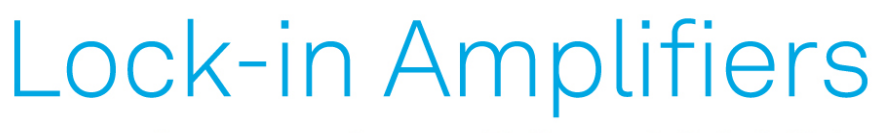

... and more, from DC to $600 \mathrm{MHz}$

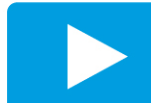

Watch 


\title{
Mathematical modeling of melting during laser materials processing
}

\author{
J. Xie and A. Kar \\ Center for Research and Education in Optics and Lasers (CREOL), Department of Mechanical, Materials \\ and Aerospace Engineering, University of Central Florida, 4000 Central Florida Boulevard, Orlando, \\ Florida 32816-2700
}

(Received 24 April 1996; accepted for publication 27 December 1996)

\begin{abstract}
Melting is encountered in almost all laser materials processing. This article deals with a one-dimensional heat conduction problem to investigate the melting rate during laser materials processing. The problem is solved approximately to obtain a correlation among melt depth, power density, and laser irradiation time. Based on this correlation, the dynamics of melting, a relationship between the melt depth and power density and an average melting velocity are expressed by simple analytic formulas. These expressions are further simplified for high power densities $\left(I \geqslant 10^{9}\right.$ $\mathrm{W} / \mathrm{m}^{2}$ ). The times to reach the melting and boiling temperatures at the surface of the workpiece are also calculated. () 1997 American Institute of Physics. [S0021-8979(97)03307-0]
\end{abstract}

\section{INTRODUCTION}

Laser is used extensively for various types of materials processing. In almost all cases, the material is melted and partially vaporized. A proper understanding of these phase change processes is necessary to achieve high quality materials processing with lasers. When laser is irradiated on a material surface, a portion of laser energy is absorbed and conducted into the interior of the material. If the absorbed energy is high enough, material surface will melt and the melting front will propagate into the workpiece. Boiling can also occur at the free surface of the melt.

The laser melting process can be simplified as onedimensional heat flow problem ${ }^{1}$ with the assumptions that the diameter of the laser beam is large enough compared to the regions of interest. To simplify the analysis for the heat transfer problem, it is also necessary to assume that the radiation emitted by the surface is negligible ${ }^{1-3}$ and that the thermophysical properties of the materials are independent of temperature. ${ }^{1-5}$ Carslaw and Jaeger ${ }^{6}$ discussed the melting of a semi-infinite body with constant thermophysical properties, and obtained an analytic solution for Dirichlet boundary conditions. They also presented an approximate series solution for the solidification of a semi-infinitely large liquid mass which was initially at its melting temperature and whose surface was exposed to a uniform heat flux. $\mathrm{Lax}^{4}$ studied the temperature rise under a steady-state condition due to a stationary Gaussian beam in a semi-infinite cylindrical medium. Bell $^{7}$ developed a one-dimensional thermal model for laser annealing over a wide range of laser pulse duration and absorption coefficients. Ready ${ }^{1}$ computed the temperature rise with no liquid phase change, and the depth due to pulsedlaser irradiation. El-Adawi $i^{2,3}$ presented results concerning the thickness of the melted layer and the rate of melting for very short irradiation times. On the three-dimensional mathematical model of laser heating, Kar and Mazumder ${ }^{8}$ presented a model to determine the transient temperature distribution during laser heating of uniformly moving finite slabs.

In this study, a one-dimensional heat conduction problem is solved approximately in the liquid and solid regions, neglecting the surface heat loss and assuming constant thermophysical properties. The effects of laser power density and time on the melt depth and melting speed, and the times for surface to reach the melting and boiling temperature are obtained.

\section{MATHEMATICAL MODEL}

The problem of uniform laser irradiation on a material is described by a model of heat conduction in a semi-infinite slab. The model of this article is based on the following heat transfer problem and the geometry of Fig. 1 that shows the molten and solid regions and the direction of laser irradiation

$$
\begin{aligned}
& \frac{\partial^{2} T_{l}(x, t)}{\partial x^{2}}-\frac{1}{\alpha_{l}} \frac{\partial T_{l}(x, t)}{\partial t}=0, \quad 0 \leqslant x \leqslant X(t), \\
& \frac{\partial^{2} T_{s}(x, t)}{\partial x^{2}}-\frac{1}{\alpha_{s}} \frac{\partial T_{s}(x, t)}{\partial t}=0, \quad X(t) \leqslant x<\infty, \\
& T_{l}(x, t)=T_{s}(x, t)=T_{m}, \quad x=X(t), \\
& k_{l} \frac{\partial T_{l}(x, t)}{\partial x}=k_{s} \frac{\partial T_{s}(x, t)}{\partial x}-\rho L \frac{d X(t)}{d t}, \quad x=X(t), \\
& -k_{l} \frac{\partial T_{l}(x, t)}{\partial x}=A I, \quad x=0, \\
& T_{s}(x, t)=T_{0}, \quad x \rightarrow \infty, \\
& T_{s}(x, t)=T_{0}, \quad t=0, \\
& X(t)=0, \quad t=0 .
\end{aligned}
$$

Here $T_{i}, \alpha_{i}$, and $k_{i}$ are temperature, thermal diffusivity, and thermal conductivity of the $i$ th phase, respectively, where $i=l$ and $i=s$ represent the liquid and solid phase, respectively. The term $x$ is the distance from the surface of the workpiece, $t$ is the irradiation time, $T_{m}$ is the melting point, $\rho$ is the density, $L$ is the latent heat of fusion, $T_{0}$ is the initial temperature, $X(t)$ is the distance from the substrate surface to the solid-liquid interface, $I$ is the laser power density, and $A$ is the absorptivity of materials. The product of the incident laser power density and the absorptivity of the material is the absorbed energy of laser.

The above-mentioned equations are a set of nonlinear partial differential equations due to the nonlinearity of the 


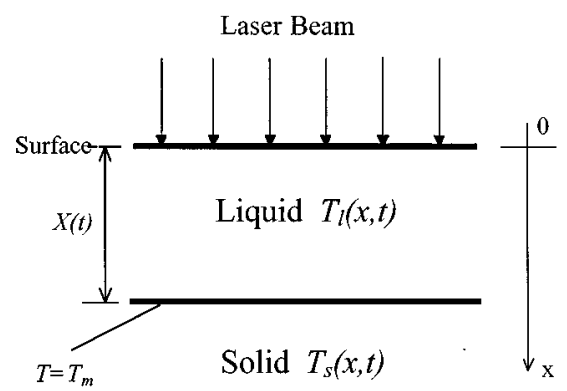

FIG. 1. A semi-infinite slab of laser irradiation.

Stefan condition (4). An approximate series solution for the solidification of a semi-infinitely large liquid mass was given by Carslaw and Jaeger, ${ }^{6}$ which is valid for low intensity irradiation. Some researchers ${ }^{9-14}$ discussed the onedimensional heat conduction problem with phase change in the case of laser irradiation. Cohen ${ }^{9,10}$ solved the problem with an assumption that the thermal conductivity and diffusivity in the solid and liquid phases are the same, and the location of the melting front was given by

$$
X(t)=\frac{0.16 I}{\rho L}\left(t-t_{m}\right),
$$

where $t$ is the time from the start of the laser irradiation and $t_{m}$ is the time to start melting at the substrate surface. The time $t_{m}$ is given ${ }^{9,10}$

$$
t_{m}=\frac{\pi k_{s}^{2} T_{m}^{2}}{4 \alpha_{s} I^{2}} .
$$

Another solution for the phase change problem in spherical coordinates due to a point source was obtained under the assumption of constant thermophysical properties and a Stefan number less than unity, ${ }^{14}$ and the quasi-steady-state solution for the solid-liquid interface was

$$
X(t)=\left(\frac{3 Q t}{2 \pi \rho L}\right)^{1 / 3},
$$

where $Q$ is the power of the point source.

A relationship among the melt depth, absorbed power density, and irradiation time are obtained by solving the heat transfer problem given by expressions (1)-(8). As pointed out earlier, the absorbed power density depends on the absorptivity of the workpiece. A discussion on the absorptivity of laser can be found in Ref. 15.

\section{METHOD OF SOLUTION}

Sharma et al. ${ }^{16}$ obtained an approximate solution for a one-dimensional phase-change heat conduction problem with time-dependent surface temperature. This procedure is extended in this article to heat flux boundary condition involving laser irradiation to solve the one-dimensional phasechange problem given by expressions (1)-(8). In this procedure, we first assume a temperature distribution which satisfies the boundary and interface conditions (3)-(6), and satisfies the governing heat conduction equations at some specific points such as $x=0$ and $x=X(t)$. This type of approximation provides a temperature profile at the boundary within $20 \%$ of the correct value for the problem solved in Ref. 16. In the liquid metal region, we assume a temperature profile which satisfies the boundary conditions (3) and (5), that is

$$
\begin{aligned}
T_{l}(x, t)= & T_{m}-\frac{A I}{k_{l}}[x-X(t)]+\psi(t)\left[x^{2}-X^{2}(t)\right], \\
& 0 \leqslant x \leqslant X(t) .
\end{aligned}
$$

By using expression (12), Eq. (1) is satisfied at $x=0$ to obtain the following expression for $\psi(t)$ :

$$
\psi(t)=\frac{A I}{2 \alpha_{l} k_{l}\left(1+\frac{X(t)}{\alpha_{l}} \frac{d X(t)}{d t}\right)} \frac{d X(t)}{d t} .
$$

So the temperature profile in the liquid region is

$$
\begin{aligned}
T_{l}(x, t)= & T_{m}-\frac{A I}{k_{l}}[x-X(t)]+\frac{A I}{2 \alpha_{l} k_{l}\left[1+\frac{X(t)}{\alpha_{l}} \frac{d X(t)}{d t}\right]} \\
& \times \frac{d X(t)}{d t}\left[x^{2}-X^{2}(t)\right], \quad 0 \leqslant x \leqslant X(t) .
\end{aligned}
$$

In the solid metal region, we assume a temperature profile which satisfies the boundary conditions (3) and (6), that is

$$
\begin{aligned}
T_{s}(x, t)= & T_{m}-\left(T_{m}-T_{0}\right)\{1-\exp [-b(t)(x-X(t))]\}, \\
& X(t) \leqslant x<\infty .
\end{aligned}
$$

By using expression (15), Eq. (2) is satisfied at $x=X(t)$ to obtain the following expression for $b(t)$ :

$$
b(t)=\frac{1}{\alpha_{s}} \frac{d X(t)}{d t} .
$$

So the temperature distribution in the solid metal region is given by

$$
\begin{aligned}
T_{s}(x, t)= & T_{m}-\left(T_{m}-T_{0}\right)\left\{1-\exp \left[-\frac{1}{\alpha_{s}} \frac{d X(t)}{d t}(x-X(t))\right]\right\}, \\
& X(t) \leqslant x<\infty .
\end{aligned}
$$

Substituting Eqs. (14) and (17) into Eq. (4), the following differential equation is obtained for $X(t)$ :

$$
\frac{d X(t)}{d t}=\frac{2 A I}{\rho\left[c_{p}\left(T_{m}-T_{0}\right)+L\right]\left\{1+\sqrt{1+\frac{4 A I X(t)}{\alpha_{l} \rho\left[c_{p}\left(T_{m}-T_{0}\right)+L\right]}}\right\}},
$$


TABLE I. Thermophysical properties of metals (see Refs. 21-23).

\begin{tabular}{|c|c|c|c|c|c|c|c|}
\hline & Aluminum & Copper & Iron & Titanium & Tungsten & $\begin{array}{c}\text { Stainless } \\
\text { steel }\end{array}$ & $\begin{array}{l}\text { Fused } \\
\text { quartz }\end{array}$ \\
\hline$\rho\left(\mathrm{kg} \mathrm{m}^{-3}\right)$ & 2700 & 8960 & 7870 & 4510 & 19250 & 7900 & 2650 \\
\hline$L\left(10^{5} \mathrm{~kg}^{-1}\right)$ & 3.97 & 2.05 & 2.66 & 4.37 & 1.92 & 3.0 & 1.46 \\
\hline$T_{m}(\mathrm{~K})$ & 933 & 1358 & 1810 & 1953 & 3653 & 1700 & 1743 \\
\hline$T_{\nu}(\mathrm{K})$ & 2723 & 2833 & 3273 & 3533 & 6203 & 3273 & 2270 \\
\hline$k_{s}\left(\mathrm{Wm}^{-1} \mathrm{~K}^{-1}\right)$ & 226 & 397 & 80 & 22 & 180 & 17 & 1.67 \\
\hline$\alpha_{s}\left(10^{-6} \mathrm{~m}^{2} \mathrm{~s}^{-1}\right)$ & 96.8 & 115 & 22.7 & 9.6 & 68 & 4 & 0.73 \\
\hline$k_{l}\left(\mathrm{Wm}^{-1} \mathrm{~K}^{-1}\right)$ & 92 & 170 & 41.5 & 28 & 71 & 30.4 & $2.87^{\mathrm{a}}$ \\
\hline$\alpha_{l}\left(10^{-6} \mathrm{~m}^{2} \mathrm{~s}^{-1}\right)$ & 38 & 43 & 7.6 & 8.23 & 24.6 & 4.9 & $1.5^{\mathrm{a}}$ \\
\hline
\end{tabular}

${ }^{\mathrm{a}}$ Data at $1500 \mathrm{~K}$.

where $c_{p}$ is the specific heat of materials in solid phase. Solving Eq. (18) with the boundary condition (8), the penetration depth $X(t)$ can be expressed as a function of the power density $I$ and irradiation time $t$ as follows:

$$
\begin{aligned}
X(t)= & {\left[-\frac{b_{0}}{2}+\left(\frac{b_{0}^{2}}{4}+\frac{a_{0}^{3}}{27}\right)^{1 / 2}\right]^{1 / 3} } \\
& +\left[-\frac{b_{0}}{2}-\left(\frac{b_{0}^{2}}{4}+\frac{a_{0}^{3}}{27}\right)^{1 / 2}\right]^{1 / 3}-\frac{\alpha_{l} m_{s}}{16 A I},
\end{aligned}
$$

where

$$
\begin{aligned}
a_{0}= & \frac{3 \alpha_{l}^{2} m_{s}^{2}}{256(A I)^{2}}\left(\frac{192(A I)^{2} t}{\alpha_{l} m_{s}^{2}}+31\right), \\
b_{0}= & -\frac{\alpha_{l}}{8 A I}\left[\frac{\alpha_{l}^{2} m_{s}^{3}}{256(A I)^{2}}\left(\frac{288 A^{2} I^{2} t}{\alpha_{l} m_{s}^{2}}+47\right)\right. \\
& \left.+\frac{t\left(18 A^{2} I^{2} t+3 \alpha_{l} m_{s}^{2}\right)}{m_{s}}\right], \\
m_{s}= & \rho\left[c_{p}\left(T_{m}-T_{0}\right)+L\right] .
\end{aligned}
$$

Equation (19) represents a relationship among the melt depth $X(t)$, absorbed laser power density $A I$, and laser irradiation time $t$. It should be noted that Eq. (19) is obtained by approximating the temperature profiles as given by expressions (12) and (15). To study the effect of such approximation, another temperature profile is examined in the liquid region. This temperature profile, which satisfies the governing Eq. (1) and the boundary conditions (3) $-(5)$, is given by

$$
\begin{aligned}
T_{l}= & T_{m}-\frac{A I}{k_{l}}[x-X(t)] \\
& +\frac{A I}{2 k_{l} \alpha_{l}\left[2+\frac{X(t)}{2 \alpha_{l}} \frac{d X(t)}{d t}\right]} \frac{d X(t)}{d t}\left[\frac{x^{3}}{X(t)}-x^{2}\right], \\
& 0 \leqslant x \leqslant X(t) .
\end{aligned}
$$

Following the same procedure as above, the melting rate and melt depth are found to be

$$
\frac{d X(t)}{d t}=\frac{2 A I}{\left[k_{s}\left(T_{m}-T_{0}\right) / \alpha_{s}+\rho L\right]\left\{1+\sqrt{1+\frac{A I X(t)}{\alpha_{l}\left[k_{s}\left(T_{m}-T_{0}\right) / \alpha_{s}+\rho L\right]}}\right\}}
$$

and

$$
\begin{aligned}
X(t)= & {\left[-\frac{b_{1}}{2}+\left(\frac{b_{1}^{2}}{4}+\frac{a_{1}^{3}}{27}\right)^{1 / 2}\right]^{1 / 3} } \\
& +\left[-\frac{b_{1}}{2}-\left(\frac{b_{1}^{2}}{4}+\frac{a_{1}^{3}}{27}\right)^{1 / 2}\right]^{1 / 3}-\frac{\alpha_{l} m_{s}}{16 A I},
\end{aligned}
$$

where

$$
a_{1}=\frac{3 \alpha_{l}^{2} m_{s}^{2}}{16(A I)^{2}}\left(\frac{48(A I)^{2} t}{\alpha_{l} m_{s}^{2}}+31\right),
$$

$$
\begin{aligned}
b_{1}= & -\frac{\alpha_{l}}{A I}\left[\frac{\alpha_{l}^{2} m_{s}^{3}}{32(A I)^{2}}\left(\frac{72 A^{2} I^{2} t}{\alpha_{l} m_{s}^{2}}+47\right)\right. \\
& \left.+\frac{3 t\left(3 A^{2} I^{2} t+2 \alpha_{l} m_{s}^{2}\right)}{m_{s}}\right], \\
m_{s}= & \rho\left[c_{p}\left(T_{m}-T_{0}\right)+L\right] .
\end{aligned}
$$

\section{RESULTS AND DISCUSSION}

Results are obtained by using Eqs. (18), (19), (21), and (22) for various materials with thermophysical properties and absorptivities as listed in Tables I and II. All of the results of 


\begin{tabular}{|c|c|c|c|c|c|c|}
\hline & \multicolumn{3}{|c|}{ Room temperature } & \multicolumn{3}{|c|}{$\begin{array}{l}\text { Melting temperature } \\
\text { (Liquid phase) }\end{array}$} \\
\hline & $\begin{array}{l}\mathrm{CO}_{2} \\
\text { Laser }\end{array}$ & COIL & $\begin{array}{l}\text { YAG } \\
\text { Laser }\end{array}$ & $\begin{array}{c}\mathrm{CO}_{2} \\
\text { Laser }\end{array}$ & COIL & $\begin{array}{l}\text { YAG } \\
\text { Laser }\end{array}$ \\
\hline Aluminum & 1.86 & 5.28 & 5.88 & 6.4 & 18.2 & 20.2 \\
\hline Copper & 1.55 & 4.39 & 4.89 & 5.1 & 14.5 & 16.1 \\
\hline Iron & 3.07 & 8.72 & 9.71 & 13.0 & 36.9 & 41.1 \\
\hline Nickel & 4.70 & 13.36 & 14.88 & 10.3 & 29.2 & 32.6 \\
\hline Titanium & 8.13 & 23.07 & 25.70 & 13.7 & 38.9 & $43.3^{\mathrm{b}}$ \\
\hline Carbon steel & 2.75 & 7.80 & 8.69 & 12.1 & 34.1 & $38.2^{\mathrm{a}}$ \\
\hline Stainless steel & 9.72 & 27.57 & 30.72 & 14.0 & 39.7 & $44.2^{\mathrm{b}}$ \\
\hline
\end{tabular}

this section are based on Eqs. (18) and (19), unless stated otherwise, and $\mathrm{CO}_{2}$ laser with a wavelength of $10.6 \mu \mathrm{m}$.

\section{A. Laser melting process}

Experimental studies for laser drilling of fused quartz ${ }^{17}$ and sapphire, ${ }^{18}$ and spot welding of stainless steel ${ }^{19}$ showed that melt depth increased rapidly at the beginning of laser irradiation and then slowly after a certain time.

A similar trend is also exhibited by Eqs. (19) and (22). These two equations represent the dynamics of the laser melting process. The analytical results obtained from Eq. (19) are compared to the experimental data for laser drilling of fused quartz ${ }^{17}$ as shown in Fig. 2. The curves are plotted with an assumption that absorptivity of fused quarts is $60 \%$. This figure shows a reasonably good agreement between the theory and experiment. For large irradiation times, the theoretical results seem to overestimate the melt depth. This may be due to the fact that the effects of vapor and plasma, which block the incident laser and absorb a portion of laser energy, are ignored in this article. Therefore, the models represented by Eqs. (19) and (22) are accurate when the vapor or plasma is not very strong, which is usually the case at the beginning of the irradiation process.

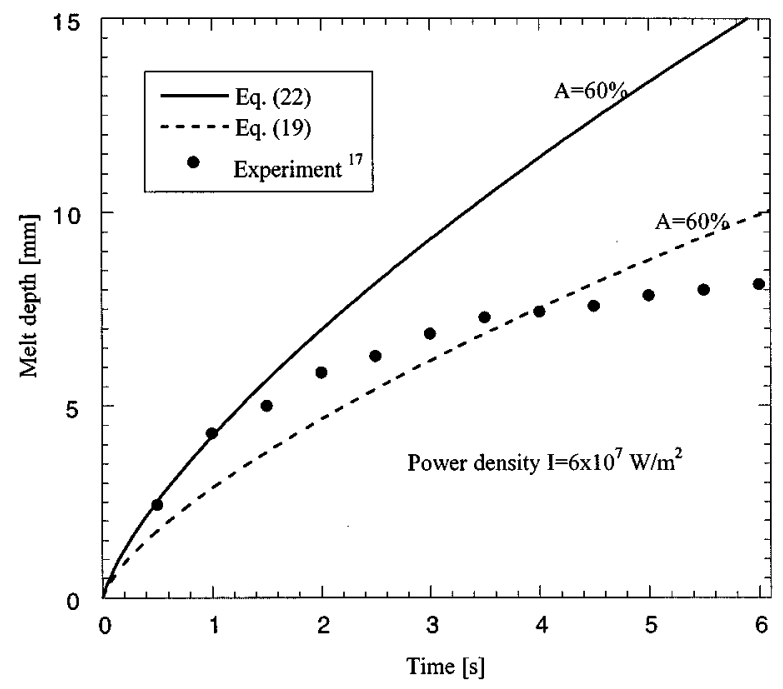

FIG. 2. Variation of melt depth with laser irradiation time for fused quartz.
The variations of melt depth and melting velocity with time for some metals are shown in Figs. 3 and 4. At the beginning, the melting velocity is high and then decreases to a low value. The trend is the same as those observed in experimental studies. ${ }^{17-19}$ The average melting velocity, $\bar{\nu}$ can be obtained by integrating Eq. (18), that is,

$$
\bar{\nu}=\frac{1}{X} \int_{0}^{X} \frac{d X}{d t} d X
$$

where $X$ is the melting depth. Substituting Eq. (18) into Eq. (23) and integrating it, the average melting velocity is found to be

$$
\begin{aligned}
\bar{\nu}= & \frac{\alpha_{l}}{X}\left\{\sqrt{1+\frac{4 A I}{\alpha_{l} \rho\left[c_{p}\left(T_{m}-T_{0}\right)+L\right]} X}\right. \\
& \left.-\ln \left[1+\sqrt{1+\frac{4 A I}{\alpha_{l}\left[c_{p}\left(T_{m}-T_{0}\right)+L\right]} X}\right]-(1-\ln 2)\right\} .
\end{aligned}
$$

Equation (24) is an expression for the average melting velocity which is a function of the laser power density, melt depth, and thermophysical properties of materials.

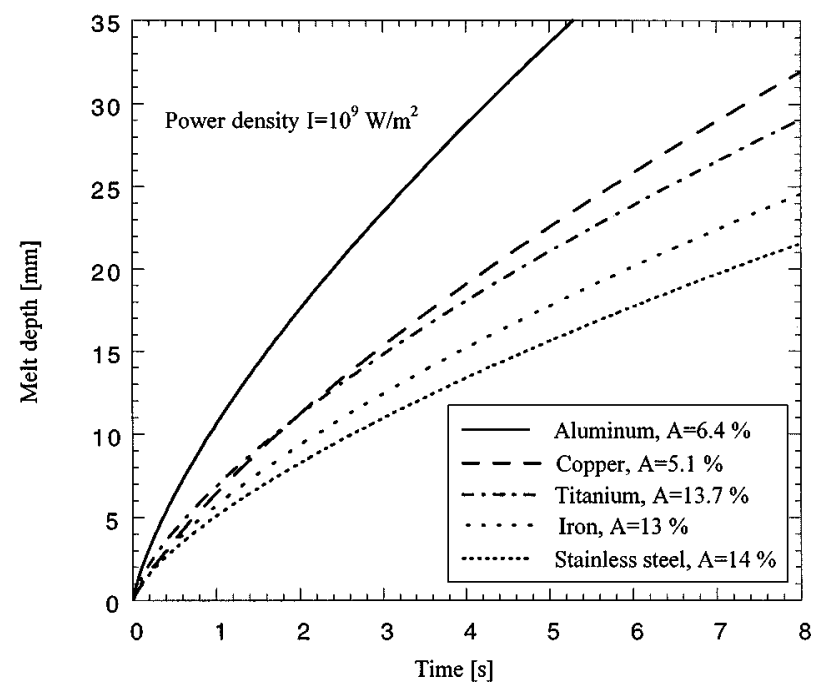

FIG. 3. Variation of melt depth with laser irradiation time for metals. 


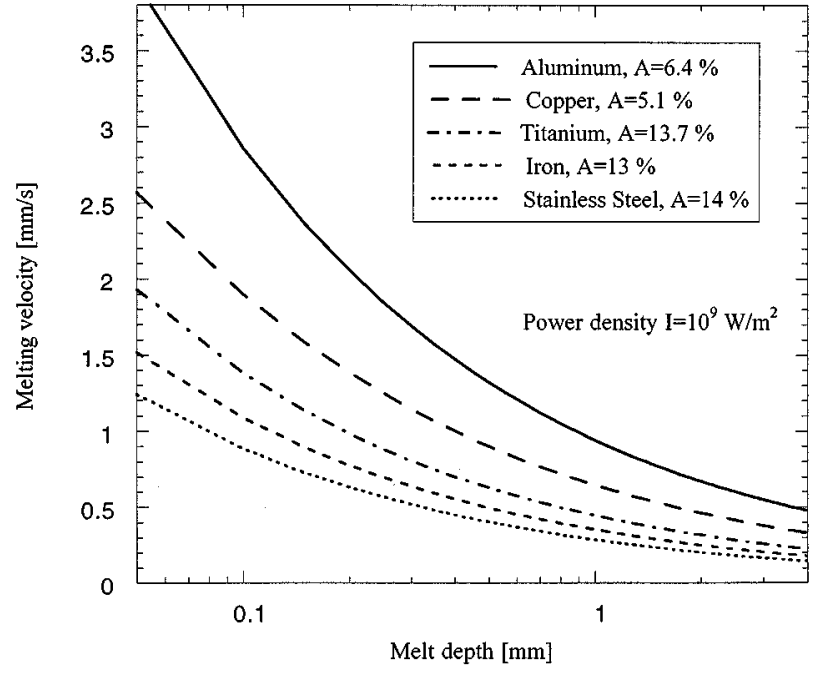

FIG. 4. Dynamics of melt depth of laser irradiation.

\section{B. Effect of laser power density on melt depth}

The melt depth is directly related to the laser power density. This relationship can be obtained from Eq. (19) for a given value of laser irradiation time as shown in Fig. 5. The melt depth increases rapidly with increasing power density when the power density is low, and increases slowly at higher power densities. In the case of laser welding, the melt depth increases in a similar way when the laser power increases. ${ }^{18-20}$ It should be noted that the laser beam moves relative to the workpiece in the case of laser welding, but the present model is based on stationary laser beam and workpiece. In spite of this difference, the results of this model can be applied to the case of laser welding by appropriately choosing the irradiation time. For example, the laser irradiation time, $t$, of this model can be replaced by the lasersubstrate interaction time, $t_{0}=D_{0} / \nu_{0}$ for the case of laser welding, where $D_{0}$ is the laser beam diameter and $\nu_{0}$ is the welding speed. The results of Fig. 5 show that the relation-

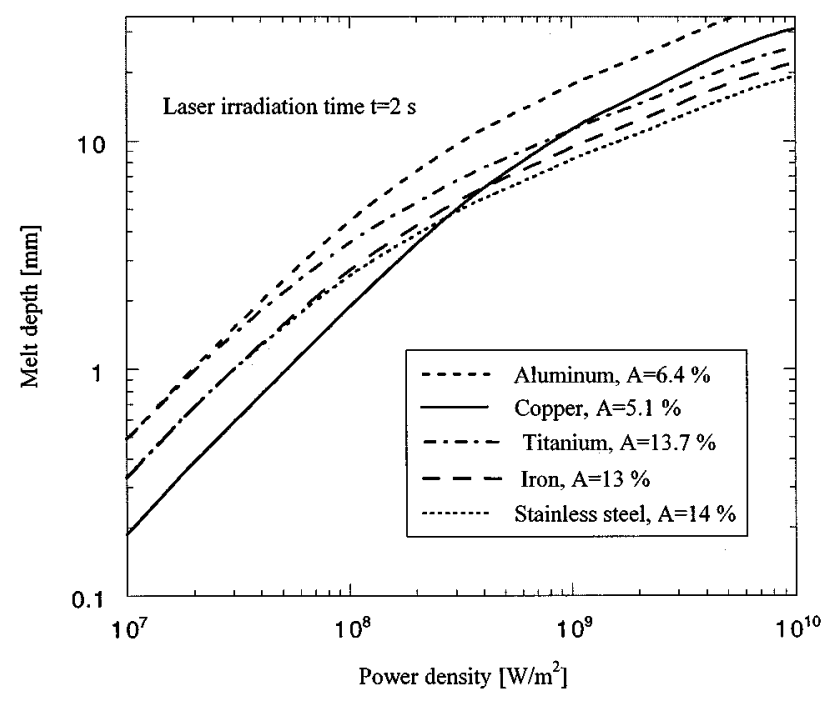

FIG. 5. Variation of melt depth with laser power density.

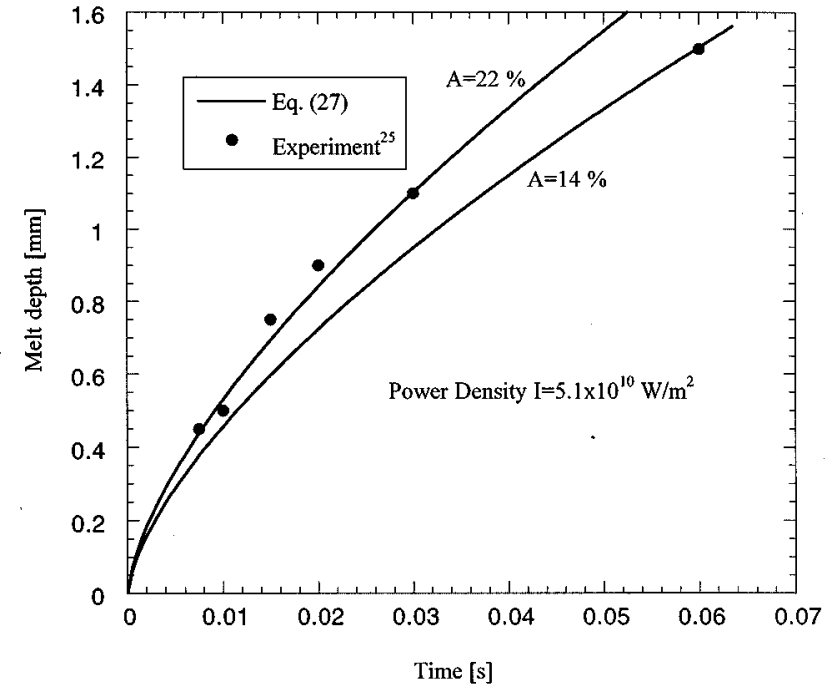

FIG. 6. Variation of melt depth with laser irradiation for 304 stainless steel.

ship between the melt depth and power density is not a simple form of either parabolic or exponential.

Based on the thermophysical properties ${ }^{21-23}$ of different materials as shown in Table I, we find that

$$
\frac{A I X}{\alpha_{l} \rho\left[c_{p}\left(T_{m}-T_{0}\right)+L\right]} \gg 1
$$

when the power density $I \geqslant 10^{9} \mathrm{~W} / \mathrm{m}^{2}$. Equation (18) can then be simplified as

$$
\frac{d X(t)}{d t}=\left\{\frac{\alpha_{l} A I}{\rho\left[c_{p}\left(T_{m}-T_{0}\right)+L\right] X(t)}\right\}^{1 / 2} .
$$

The solution of Eq. (26) that satisfies boundary condition (8) is

$$
X(t)=1.31\left(\frac{\alpha_{l} A I t^{2}}{\rho\left[c_{p}\left(T_{m}-T_{0}\right)+L\right]}\right)^{1 / 3} .
$$

The average melting velocity for the workpiece with a thickness of $X_{0}$, can be obtained by integrating Eq. (26) as follows:

$$
\bar{\nu}=2\left\{\frac{\alpha_{l} A I}{\rho\left[c_{p}\left(T_{m}-T_{0}\right)+L\right] X}\right\}^{1 / 2} .
$$

Equations (26), (27), and (28) are valid for high laser power densities $\left(I \geqslant 10^{9} \mathrm{~W} / \mathrm{m}^{2}\right)$. Equation (28) shows that the average melting velocity is proportional to the square root of the power density, and that it decreases as the melt depth increases. Such a trend has been observed in experimental studies conducted by Bergmann and Hartmann. ${ }^{24}$ Equation (27) provides a relationship among the melt depth $X$, power density $I$, and irradiation time $t$ for high power densities $\left(I \geqslant 10^{9} \mathrm{~W} / \mathrm{m}^{2}\right)$. The theoretical results are compared to the welding experimental data of 304 stainless steel $\mathrm{l}^{25}$ and copper alloy (NARloy-Z, $\mathrm{Cu} 3 \mathrm{wt} \% \mathrm{Ag}-0.5 \mathrm{wt} \% \mathrm{Zr})^{26}$ as shown in Figs. 6 and 7, where the laser irradiation time in the welding experiment is determined from $t_{0}=D_{0} / \nu_{0}$. The absorptivity of stainless steel at just below melting temperature (solid state) in Table II is $14 \%$. This value for the liquid state 


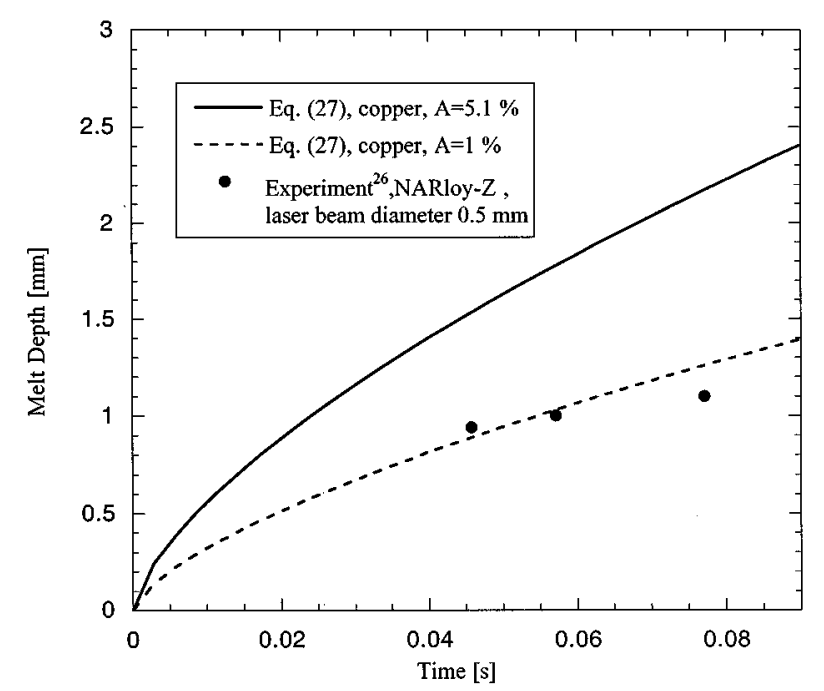

FIG. 7. Variation of melt depth with laser irradiation time for copper and NARloy-Z.

at melting temperature should be higher because there is a jump in the absorptivity when the solid phase changes to the liquid phase. Also, Table II shows theoretical values of the absorptivity which may be different from the actual absorptivities. For this reason, Figs. 6 and 7 are plotted for two different absorptivities, and the model predictions are found to agree well with experimental results.

The validity of the model of this article is also examined by comparing Eq. (27) to Metzbower's empirical relation for HY 130 and ASTM A710 steels as given below ${ }^{27}$

$$
X=\frac{0.10618 P}{k T_{m}}\left(\frac{\alpha}{\nu_{0} D_{0}}\right)^{1.2056}
$$

where $P$ is laser power. This relation can be rewritten as

$$
X=\frac{0.0834 I \alpha^{0.2056} t^{1.2056}}{\rho c_{p} T_{m} D_{0}^{0.4112}} .
$$

The functional dependence of the melt depth on the laser intensity and thermophysical properties are similar in Eqs. (27) and (30), and only the exponents are different.

It is interesting to note in Fig. 5 that the melt depth of copper is less than most metals at low power densities and greater than many metals at high power densities. Copper is generally difficult to melt because of its high thermal conductivity and low absorptivity compared to most of the metals. At low power densities, the melting velocity is low compared to the speed of heat conduction in the substrate. Therefore, the conduction loss of the input laser energy will be more in copper than in most of the metals. This will lead to lower melt depth for copper at low power densities as shown in Fig. 5. On the other hand, at high power densities, the melting velocity is high compared to the rate of heat loss due to conduction in the workpiece. Therefore, the conduction loss in the solid portion of the workpiece is less than in the case of low power densities. Most of the laser energy deposited at the melt surface will be conducted to the liquidsolid interface due to high thermal conductivity of copper, and will be utilized to melt the substrate. This will give rise

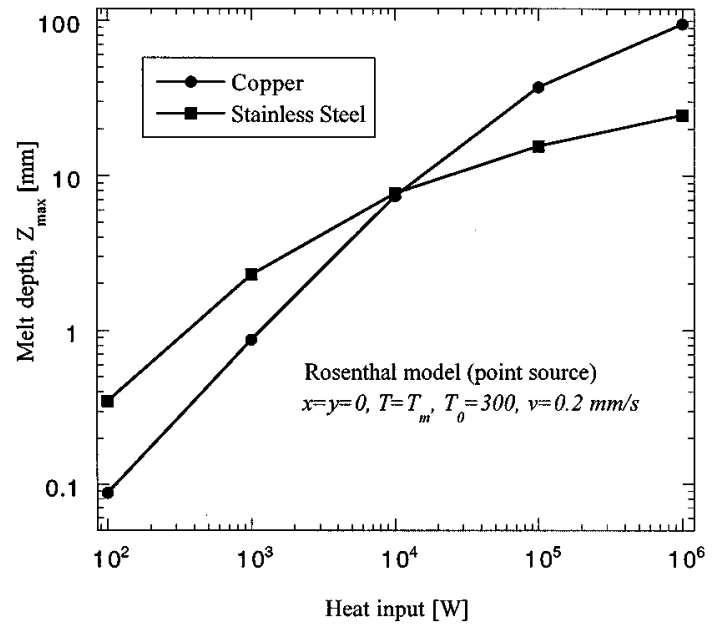

FIG. 8. Variation of penetration depth with welding speed for copper and stainless steel based on Rosenthal's model (see Ref. 28), where the thermophysical properties of liquid phase are used.

to higher melt depth for copper at higher power densities as shown in Fig. 5. Similar thermal process is responsible for higher melt depth in aluminum shown in Fig. 5. Additionally, aluminum and copper have lower melting temperatures and latent heat of fusion than many metals, which means less sensible and latent heats are required to melt these two metals. This can also contribute to higher melt depths for copper and aluminum.

The heating phenomena in copper and stainless steel substrates are investigated by using Rosenthal's moving point heat source model. ${ }^{28}$ The maximum depth, $Z=Z_{\max }$ at $x=y=0$ for the isotherm $T=T_{m}$ is given by ${ }^{28}$

$$
\frac{2 \pi\left(T_{m}-T_{0}\right) k Z_{\max }}{Q}=\exp \left(\frac{-\nu_{0} Z_{\max }}{2 \alpha}\right),
$$

where $Q$ is total heat delivered from the point heat source to the workpiece. The depth for copper is found to be less at low heat input and more at high heat input than for stainless steel as shown in Fig. 8, where the thermophysical properties of liquid copper and stainless steel are used. A similar trend can be found if the thermophysical properties of solid copper and stainless steel are used.

It should be noted that the model of this article is based on the occurrence of melting and that the materials may not melt if the power density is very small. This means that the power density, irradiation time, or a combination of these two parameters must be large enough to induce melting for the model of this article to be applicable. The times to reach melting and boiling temperatures on the surface of materials is discussed in the next section.

\section{Melting and vaporizing time}

Due to laser irradiation on the surface of a solid material, the surface temperature increases. The time for the surface to reach melting temperature, $t_{m}$, can be obtained by ${ }^{29}$

$$
t_{m}=\frac{\pi k_{s}^{2}\left(T_{m}-T_{i}\right)^{2}}{4 \alpha_{s}(A I)^{2}}
$$


TABLE III. Times to melt and vaporize at different power densities.

\begin{tabular}{|c|c|c|c|c|c|c|}
\hline \multirow{2}{*}{$\frac{\text { Power density }\left(\mathrm{Wm}^{2}\right)}{\text { Time }(\text { second })}$} & \multicolumn{2}{|c|}{$10^{8}$} & \multicolumn{2}{|c|}{$10^{9}$} & \multicolumn{2}{|c|}{$10^{10}$} \\
\hline & $t_{m}^{\mathrm{a}}$ & $t_{\nu}$ & $t_{m}$ & $t_{\nu}$ & $t_{m}$ & $t_{\nu}$ \\
\hline Aluminum & 4.4 & 16.0 & $4.4 \times 10^{-2}$ & $1.6 \times 10^{-1}$ & $4.4 \times 10^{-4}$ & $1.6 \times 10^{-3}$ \\
\hline Copper & 46.1 & 102.2 & $4.6 \times 10^{-1}$ & 1.02 & $4.6 \times 10^{-3}$ & $1.0 \times 10^{-2}$ \\
\hline Iron & 3.0 & 21.9 & $3.0 \times 10^{-2}$ & $2.2 \times 10^{-1}$ & $3.0 \times 10^{-4}$ & $2.2 \times 10^{-3}$ \\
\hline Titanium & 0.6 & 2.0 & $5.8 \times 10^{-3}$ & $2.0 \times 10^{-2}$ & $5.8 \times 10^{-5}$ & $2.0 \times 10^{-4}$ \\
\hline Stainless steel 304 & 0.56 & 2.86 & $5.6 \times 10^{-3}$ & $2.9 \times 10^{-2}$ & $5.6 \times 10^{-5}$ & $2.9 \times 10^{-4}$ \\
\hline Fused quartz ${ }^{\mathrm{b}}$ & $1.75 \times 10^{-3}$ & $3.69 \times 10^{-3}$ & $1.8 \times 10^{-5}$ & $3.7 \times 10^{-5}$ & $1.8 \times 10^{-7}$ & $3.7 \times 10^{-7}$ \\
\hline
\end{tabular}

${ }^{\mathrm{a} E q .}$ (32) is used to determine $t_{m}$.

${ }^{\mathrm{b}}$ Thermal properties at $1500 \mathrm{~K}$ are used as that in liquid phase (melting point $1743 \mathrm{~K}$ ) and the absorptivity of $60 \%$ is assumed.

where $T_{i}$ is an initial temperature of the substrate. After the surface starts melting, the temperature distribution in the liquid region, $T_{l}$, and the location of the solid-liquid interface can be, respectively, expressed by Eqs. (21) and (22). The condition for the surface to reach boiling temperature is $T_{l}=T_{\nu}$ at $x=0$, where $T_{\nu}$ is the boiling temperature of the workpiece. Substituting this condition into Eqs. (21) and (22), the time at which the surface of the workpiece begins to vaporize, can be written as

$$
\begin{aligned}
t_{\nu}^{\prime}= & \frac{k_{l}\left(T_{\nu}-T_{m}\right) \rho}{2(A I)^{2}}\left[c_{p}\left(T_{m}-T_{0}\right)+L\right]+\frac{\alpha_{l} \rho}{3(A I)^{2}} \\
& \times\left[c_{p}\left(T_{m}-T_{0}\right)+L\right] \\
& \times\left\{\left[1+\frac{k_{l}\left(T_{\nu}-T_{m}\right)}{\alpha_{l} \rho\left[c_{p}\left(T_{m}-T_{0}\right)+L\right]}\right]^{3 / 2}-1\right\} .
\end{aligned}
$$

It should be noted that, according to the model of this article $t_{v}^{\prime}$ represents the time for temperature rise from melting to boiling point at the substrate surface. Therefore, the total time, $t_{\nu}$, for the substrate surface to reach boiling temperature from the start of laser irradiation is given by

$$
t_{\nu}=t_{\nu}^{\prime}+t_{m} \text {. }
$$

The times to start melting and boiling of some materials are shown in Table III.

As shown in Table III, the time to initiate boiling is very short for high laser power densities. This means that vapor or plasma dominates the process after a short time of laser irradiation. Vapor or plasma will affect laser-material interactions. Since the effects of vapor or plasma are not considered in this study, the model of this article will overestimate the results at high power densities.

\section{CONCLUSIONS}

(1) A relationship among the melt depth, power density, and laser irradiation time is obtained by an approximate solution to one-dimensional heat conduction problem under laser beam irradiation.

(2) The dynamics of the melting process is derived from the approximate solution. At the beginning of laser irradiation, the melt depth increases rapidly with time and then increases slowly.

(3) The relationship between the melt depth and power density of laser obtained by the approximate solution shows that the melt depth increases rapidly with power density and then increases slowly for higher power densities.

(4) The average melting velocity, which can be expressed as a function of power density, melt thickness, and thermophysical properties of materials, increases as the power density increases, and decreases as the melt depth increases.

(5) For high power densities $\left(I \geqslant 10^{9} \mathrm{~W} / \mathrm{m}^{2}\right)$, the relationship among the melt depth $X$, power density $I$, and irradiation time $t$ can be expressed by a simple expression as given by Eq. (27).

(6) For high power densities $\left(I \geqslant 10^{9} \mathrm{~W} / \mathrm{m}^{2}\right)$, the average melting velocity can be denoted by a simple expression as given by Eq. (28).

(7) The times to reach melting and boiling temperatures at the substrate surface are found to be very short (about a few microseconds) for high power densities.

\section{ACKNOWLEDGMENTS}

The authors gratefully acknowledge the financial support provided by the Center for Research and Education in Optics and Lasers (CREOL) and the Department of Mechanical, Materials and Aerospace Engineering, University of Central Florida.

${ }^{1}$ J. F. Ready, J. Appl. Phys. 36, 462 (1965).

${ }^{2}$ M. K. El-Adawi, J. Appl. Phys. 60, 2256 (1986).

${ }^{3}$ M. K. El-Adawi and S. A. Shalaby, J. Appl. Phys. 60, 2260 (1986).

${ }^{4}$ M. Lax, J. Appl. Phys. 48, 3919 (1977).

${ }^{5}$ H. E. Cline and T. R. Anthony, J. Appl. Phys. 48, 3895 (1977).

${ }^{6}$ H. S. Carslaw and J. C. Jaeger, Conduction of Heat in Solid (Oxford University Press, New York, 1959).

${ }^{7}$ A. E. Bell, RCA Rev. 40, 295 (1979).

${ }^{8}$ A. Kar and J. Mazumder, J. Appl. Phys. 65, 2923 (1989).

${ }^{9}$ M. I. Cohen, J. Franklin J. Franklin Inst. 283, 271 (1967).

${ }^{10}$ M. I. Cohen and J. P. Epperson, Adv. Electron. Electron Phys., Suppl. 4, 139 (1968).

${ }^{11}$ J. F. Ready, Effect of High-power Laser Radiation (Academic, New York, 1971).

${ }^{12}$ R. Mehrabian, S. Kou, S. C. Hsu, and M. Munitz, Laser-solid Interactions and Laser Processing, edited by S. D. Ferris, H. J. Leamy, and J. M. Poate (AIP, New York, 1979), p. 129.

${ }^{13}$ W. W. Duley, Laser Processing and Analysis of Materials (Plenum, New York, 1983)

${ }^{14}$ M. A. Shannon, B. Rubinksy, and R. E. Russo, J. Appl. Phys. 75, 1473 (1994).

${ }^{15}$ Y. Arata and I. Miyamoto, Trans. Jpn. Welding Soc. 3, 152 (1972).

${ }^{16}$ O. P. Sharma, M. Rotenberg, and S. S. Penner, AIAA J. 5, 667 (1967).

${ }^{17}$ W. W. Duley and W. A. Young, J. Appl. Phys. 44, 4236 (1973). 
${ }^{18}$ J. F. Ready, Industrial Applications of Lasers (Academic, New York, 1978), pp. 378 and 403.

${ }^{19}$ V. V. Semak, J. A. Hopkins, M. H. McCay, and T. D. McCay, in Proceeding of the International Congress on the Applications of Laser and Electron-Optics, 1994 (ICALEO'94): Laser Materials Processing, edited by T. D. McCay, A. Matsunawa, and H. Hugel (Laser Institute of America, Orlando, Florida, 1994), Vol. 2500, pp. 830-837.

${ }^{20}$ J. Mazumder, Laser Materials Processing, edited by M. Bass (NorthHolland, Amsterdam, 1983), pp. 120-124.

${ }^{21}$ Y. S. Touloukian, R. W. Powell, C. Y. Ho, and P. G. Klemens, Thermophysical Properties of High Temperature Solid Materials (Macmillan, New York, 1976).

${ }^{22}$ CRC Handbook of Materials Science, Vol. 1 General Properties, edited by T. Lynch (CRC, Cleveland, 1974).

${ }^{23}$ Y. S. Touloukian and C. Y. Ho, Thermophysical Properties of Selected Aerospace Materials, Part II. Thermophysical Properties of Seven Materials (Purdue University, West Lafayette, Indiana, 1977).
${ }^{24}$ H. W. Bergmann and M. Hartmann, Laser Materials Processing IV, edited by J. Mazumder, K. Mukherjee, and B. L. Mordike (The Minerals, Metals and Materials Society, Warrendale, PA, 1994), pp. 33-44.

${ }^{25}$ H. N. Bransch, in Proceeding of the International Congress on the Applications of Laser and Electron-Optics, 1992 (ICALEO'92): Laser Materials Processing (Laser Institute of America, Orlando, Florida, 1992), pp. 70-76.

${ }^{26}$ J. Singh, B. N. Bhat, R. Poorman, A. Kar, and J. Mazumder, Surf. Coat. Technol. 79, 35 (1996).

${ }^{27}$ E. A. Metzbower, P. E. Denney, and L. DeMarco, Laser Materials Processing IV, edited by J. Mazumder, K. Mukherjee, and B. L. Mordike (The Minerals, Metals and Materials Society, Warrendale, PA, 1994), pp. 205212.

${ }^{28}$ D. Rosenthal, Welding J. 20, 1941, 220-234.

${ }^{29}$ F. P. Incropera and D. P. DeWitt, Fundamentals of Heat and Mass Transfer (Wiley, New York, 1990), p. 260

${ }^{30}$ J. Xie, A. Kar, J. Rothenflue, and W. P. Latham, J. Laser Appl. (in press). 